\section{Microteaching at Home: fomento de la creatividad y el aprendizaje "lúcdico" en la Universidad en tiempos de la COVID-19}

\author{
Adrián Sánchez García \\ Universidad de Valladolid
}

Microteaching at Home: Promotion of Creativity and Lucdic Learning at University in times of COVID-19

\section{Abstract}

The COVID-19 health crisis has caused the transformation an adaptation of face-to-face teaching in distance learning. This text is born from the reflection on the experience of the subject "Early Learning of Foreign Language: English" of the "Duques de Soria" Campus of the University of Valladolid. Thus, the objectives such as the propmotion of creativity and lucdic learning (which is both 'ludic' and 'lucid') were set and practical works such as Microteaching at Home were developed, microteaching activities that instead of being carried out at university classroom with the participation of other colleagues, are carried out in the domestic environment. The results of these activities have been positive, noting that the students had worked on the contents of the subject and had creatively developed the materials, activities, storytelling techniques, etc.

Key words: Microteaching, Creativity, Lucdic Learning, English Teacher Education, University.

\section{Introducción}

Debido a la emergencia sanitaria que ha supuesto la pandemia de la COVID-19, la enseñanza presencial de gran parte del globo terráqueo se ha visto en la obligación de ser transformada, sin previo aviso, en formación a distancia. Esto ha supuesto que las distintas etapas educativas, incluida la educación superior universitaria, hayan adaptado en tiempo record todos los elementos necesarios (contenidos, metodologías, etc.) siguiendo las indicaciones que dictaban los diferentes estamentos educativos.

Estas páginas nacen de la reflexión docente en torno a la experiencia, durante estos meses de confinamiento y desescalada, en la asignatura "Aprendizaje Temprano de Lengua Extranjera: Inglés" del segundo curso del Grado en Educación Infantil del Campus "Duques de Soria" de la Universidad de Valladolid. Para situarnos en contexto, se trata de una asignatura obligatoria relacionada con el aprendizaje de la lengua inglesa y su lectoescritura, cuya evaluación se realiza en base al progreso de

\title{
MAGISTER
}

Vol. 32. Núm. I: (2020). Sección extraordinaria 
los estudiantes a través de sus prácticas, es decir, sin un examen final. Así, la adecuación de esta asignatura no ha sido extremadamente complicada en cuanto a competencias, objetivos, contenidos o evaluación, pero sí ha supuesto un cambio de mentalidad radical para todas las personas que conformamos el día a día en el aula.

\section{Objetivos y Metodología}

Después de una primera reflexión e interpretación en un entorno con alto grado de incertidumbre, los objetivos fijados a la hora de adaptar la asignatura fueron:

- Asegurar la calidad de la formación de los futuros científicos de la educación.

- Asemejar todo lo posible el modelo a distancia con una enseñanza presencial, modificándose el plan de trabajo previsto en favor del proceso de Enseñanza-Aprendizaje.

- Favorecer la implicación del profesorado de manera profesional y personal, promoviendo la motivación del alumnado tanto en la asignatura como en su vida diaria con comentarios de ánimo en las clases de la asignatura, correos electrónicos, tutorías vía Skype, foros o mensajes en el campus virtual.

- Cuidar la salud mental del alumnado, entrando en juego la visión del docente y la didáctica como potenciales sanadores sociales y defendiendo, como ya se ha hecho en otros textos, "la capacidad sanadora del sistema educativo, docente mediante, para curar a la sociedad, estableciéndose así una clara y fructífera relación escuela-comunidad" (Sánchez, 2020, p. 340). Así, en ese ir y venir de comunicación docente-discente, en la distancia no debían faltar las recomendaciones de las autoridades sanitarias y consejos sobre libros, películas y música, entre otros temas.

- Fomentar la creatividad y el aprendizaje 'lúcdico', eje principal que vertebra esta propuesta, fundamentada con las ideas que Francisco (2016) plasmó en su tesis doctoral.

De acuerdo con Francisco (2016), "Crisis y creatividad, van, por tanto, hand in hand; para bien o para mal, esto parece ser un hecho probadamente cierto a lo largo de la historia de la humanidad" (p.89). En este sentido, la crisis sanitaria que estamos viviendo ha hecho necesario que la creatividad ocupe un lugar central en cualquier aspecto de nuestra vida, también en el educativo y universitario; es más, un sistema educativo adecuado tendría la capacidad para ponerse manos a la obra y de este modo la creatividad, entendida ya como un valor intrínseco en el ser humano, sería potenciada a lo largo de todas las etapas de la vida humana. Potenciada, repito, no realmente enseñada, pues ya es inherente al ser humano (Francisco, 2016, p. 138).

Pero además de lo creativo, lo "lúcdico" también adquiere gran importancia. Este concepto que designó Francisco (2016, p.280) hace referencia a:

aquello que es a la vez 'lúcido' y 'lúdico', que implica cierto grado de juego unido a un profundo deseo de 'esclarecer con la mirada' a través de las capacidades lógico-racionales que fundamentan el acto de pensar. Así, nos encontramos ante un esfuerzo sin esfuerzo, un fluir dulcemente hacia nuevos estados de entendimiento, de comprensión y, al fin y al cabo, consciencia.

Para ello, se siguieron diferentes líneas de actuación, siempre de manera planificada:

- Trabajos eminentemente teóricos, algunos ya previstos con anterioridad y otros nuevos, con ánimo de cubrir los primeros días en los que había una mayor incertidumbre y con el objetivo de adquirir las destrezas necesarias para la realización del Trabajo de Fin de Grado en un futuro, no tan lejano como el alumnado piensa. Si hablamos de formar científicos de la educación, leer diferentes textos, analizarlos, establecer conexiones y defender posicionamientos personales en base a ellos, debe ser algo presente a lo largo de sus estudios.

- Trabajos prácticos, siempre necesarios en asignaturas de didáctica, ya que aportan destrezas que no pueden ser adquiridas únicamente con conocimiento teórico y que habitualmente son el paso posterior. Dentro de ellas enmarcamos los Microteaching at Home, actividades de microenseñanza que, en vez de realizarse en el aula con la participación de otros compañeros que hacen de docentes, alumnos e incluso observadores, se realizan en el entorno doméstico. Estas actividades nos deben recordar que "no podemos olvidar jamás que, si queremos enseñar, quienes primero tenemos que estar aprendiendo constantemente somos los maestros" (Bona, 2015, p.31).

\section{MAGISTER}

Vol. 32. Núm. 1: (2020). Sección extraordinaria 
- Uso de foros en el campus virtual como elemento sustitutivo de los debates que se promueven en las aulas universitarias, donde la discusión e intercambio de opiniones, ideas y pensamientos debe estar siempre presente.

- Animar a participar en otras actividades del campus, como fue la realización de un vídeo de cinco minutos, de manera totalmente voluntaria, ejerciendo la labor de cuentacuentos para posteriormente subirlo a YouTube y que los más pequeños pudieran verlos durante el periodo de confinamiento. Así aportábamos nuestro pequeño granito de arena a la sociedad en un momento tan complicado como el que nos ha tocado vivir, además de ser algo enriquecedor para la formación de las maestras y maestros de Educación Infantil.

Centrándonos en Microteaching at Home, es la actividad principal en la que ponemos en juego la creatividad y el aprendizaje "lúcdico". Aprender "lucdicamente" fue una vía de escape para nuestro alumnado puesto que, pese a la dificultad de concentración propia del confinamiento, el aporte lúdico en trabajos universitarios que necesitan de nuestras capacidades cognitivas a pleno rendimiento, ayuda a sobrellevarlo y a aumentar la implicación del alumnado.

Esta actividad de microenseñanza, dividida en dos vídeos, supuso la aplicación de todo lo trabajado en la asignatura. Sin embargo, pese a conceder bastante libertad al alumnado, era necesario poner límites porque,

La creación es, pues, un viaje en pos del límite. Por lo tanto, situar márgenes para sentir con mayor deseo el impulso de superación creativa será una de las acciones que podemos realizar desde la Didáctica para estimular la creatividad en el aula (Francisco, 2016, p.203).

Así, en la primera actividad de Microteaching at Home, se pidió a los alumnos que se grabaran realizando parte de una sesión de inglés de Educación Infantil, que tenía que poseer como mínimo, y en un orden coherente, la realización de una asamblea, una canción, la narración de un cuento y una actividad que involucrara a todo el alumnado. En el segundo Microteaching at Home, se pidió la creación y posterior puesta en práctica de actividades para trabajar los phonics y otras donde se usará blending, siempre abordando las diferentes habilidades lingüísticas.
Para el desarrollo de las actividades de microenseñanza podían contar con la ayuda de familiares o utilizar objetos (peluches, muñecas...) y ponerles voz para simular el alumnado que está realizando la sesión. Además, podían emplear los recursos que creyeran convenientes, con el hándicap de que tenían que crear todo el material haciendo uso de su creatividad y de los elementos que tenían en casa. Asimismo, "al crear, por tanto, dejamos que al menos parte de lo que somos, lo que nos conforma, salga de nosotros, y sale de nosotros en gran medida para que seamos capaces de ver lo que antes no veíamos" (Francisco, 2016, p.93).

\section{Resultados y Discusión}

Cabe decir que durante la realización de los trabajos en esta modalidad a distancia y su posterior evaluación, el alumno debe hacerse entender y el profesor debe intentar entender, interpretar a su alumnado, su contexto y el trabajo que está realizando (animo en este punto a que los lectores se introduzcan en el campo de la Hermenéutica Analógica aplicada a la educación y a la didáctica).

En cuanto a la participación del alumnado y la calidad de los debates en los foros del campus virtual, el resultado no ha sido el esperado, quizá porque han centrado su motivación en otros trabajos o por ser debates asíncronos y con grandes periodos de tiempo para su realización, lo que puede entorpecer el intercambio de opiniones e ideas. Si nos centramos en los Microteaching at Home, los resultados han sido positivos, observándose que el alumnado había trabajado los contenidos de la asignatura y había desarrollado creativamente los materiales, actividades, técnicas de storytelling, etc.

Además, hago aquí un inciso para recordar la importancia de perder la vergüenza a estar de cara al público, puesto que "el hecho de enseñar a la gente a hablar en público delante de los compañeros sirve para que uno pueda expresar sus emociones, compartir sus pensamientos, defender sus argumentos..." (Bona, 2015, p.107), por ello son tan importantes las presentaciones orales durante los estudios universitarios. Quizá sería incluso recomendable que el docente adquiriera durante su formación los conocimientos y las habilidades que poseen los actores y profesionales del espectáculo. Así que, al igual que no es fácil realizar una exposición oral, tampoco

\section{MAGISTER}

Vol. 32. Núm. I: (2020). Sección extraordinaria 
lo es ponerse delante de una cámara y grabar un vídeo, por lo que este objetivo está cubierto.

Por su parte, como aspectos diferenciales en la formación a distancia de la que se hace presencial, cabe señalar la necesidad de transformar el trabajo en grupo en individual, al igual que con esta modalidad de microteaching los alumnos no aprenden de sus compañeros y no hay un feedback directo, ya sea por parte del profesor o de sus iguales.

\section{Conclusiones}

La creatividad ha aflorado, y debe seguir haciéndolo, en tiempos de la COVID-19, tanto dentro como fuera del ámbito educativo. En ese momento del confinamiento cuando se pide al alumnado que sea creativo y convierte su habitación, salón o jardín en un aula; transforma peluches en intrépidos alumnos de Educación Infantil; implica a sus padres, desconocedores del idioma, en su aprendizaje; pide ayuda a sus hermanos o realiza el microteaching con sus primos por videollamada, observamos que la creatividad tiene muchas vertientes y cada uno explora la que cree más adecuada, además de humanizar la educación involucrando a personas de su entorno, fomentando así "una educación que, sobre todo, se basa en el factor humano, algo que muchas veces cae en el olvido" (Bona, 2015, p.35).

También se ha intentado desarrollar una formación "lúcdica", que une lo lúdico y lo lúcido, es decir, un proceso en el que el juego (la realización de los Microteaching at Home) y la lucidez en la planificación de las actividades del mismo, desarrollan las potenciales habilidades y destrezas docentes de nuestros alumnos.

Para finalizar, añadir que, durante esta adaptación de la asignatura al modelo online, el profesorado ha tenido que atender al alumnado de la mejor manera posible, asegurando la calidad de su formación y siendo flexibles, adecuándose a este modelo con el esfuerzo que ello conlleva para profesores y alumnos. Ha sido un gran reto, pero con compromiso, esfuerzo e implicación se ha superado con creces.

\section{Referencias}

Bona, C. (2015). La Nueva Educación. Los retos y desafíos de un maestro de hoy. Barcelona: Penguin Random House Grupo Editorial, S. A. U.

Francisco, F. J. (2016). Hermenéutica Analógica, Poética del Haiku y Didáctica de la Creatividad (Una propuesta para desarrollar la interpretación, la comprensión y la creatividad literaria en el aula de Lengua Inglesa en Educación Primaria) (Tesis doctoral). Universidad de Salamanca, España. Sánchez, A. (2020). El Docente y la Didáctica como Pilares de Sanación Social. Revista Inclusiones, 7(3), 332-342.

*Autor de contacto: Adrián Sánchez García, adriansanchez94@hotmail.com

\section{MAGISTER}

Vol. 32. Núm. I: (2020). Sección extraordinaria 